Dr.

Muruganantham

Arunagirinathan*

Dr. Rekha

Mariappan

Dr. P. Magesh

\title{
RETROSPECTIVE STUDY OF CLINICOPATHOLOGICAL PARAMETERS IN
} GASTRIC CARCINOMA.

ABSTRACT Back Ground: The incidence of gastric cancer is increasing worldwide, that presents with varied symptoms and signs. To diagnose gastric cancer in early stage we need to evaluate various clinical parameters and to grade the tumour we need to correlate with expression of P2l in tissue sample.

Methods: Clinical parameters like age, sex, symptoms \& signs and tumour location of 50 patients were noted from the biopsy register and paraffin blocks with tumour of corresponding patients were evaluated for P21 expression by immunohistochemistry. Conclusion: In the present study, men were twice more commonly affected by gastric cancer than women. Most of the patients were aged above 50 years of age. P21 expression was found to be positive in most of the well differentiated grade and loss of P21 expression was noted in most of the poorly differentiated gastric adenocarcinoma.

KEYWORDS : Gastric carcinoma, Risk factors, Clinical parameters, P21 expression.

\section{INTRODUCTION:}

Adenocarcinoma of stomach used to be the second most common cancer causing death in all countries ${ }^{\text {(1). Global }}$ statistics revealed 989600 newly diagnosed cases with an average of 738000 gastric cancer deaths per year ${ }^{(2)}$. The incidence of stomach cancer varies between different countries due to varied environmental factors, socioeconomic differences, diet and Helicobacter pylori (H.pylori) infection.

Gastric cancers are usually seen over 50 years of age with highest incidence rate in the age range of 60 to 80 years $^{(3)}$. The symptoms and signs of gastric carcinoma are vague and nonspecific in early stage and hence gastric carcinoma is diagnosed late when the disease is already in advanced stage with deep muscle invasion ${ }^{(3)}$.

The analysis of P21 gene protein expression has been studied in various cancers like prostate, bladder, breast, colon, esophagus and lung for its prognostic significance and reported to have tumour suppressor activity by inhibiting the cell cycle. The regulator of cell cycle like $\mathrm{p} 21$ has been studied in gastric carcinoma patients who showed a positive expression in early stage ${ }^{(4)}$. Hence P2l can be used as one of the molecular marker for diagnosis of early gastric carcinoma.

\section{AIM AND OBJECTIVES:}

To evaluate the clinical parameters like age, sex, risk factors, presenting symptoms and tumor location in gastric carcinoma.

To analyze the histological type of gastric adenocarcinoma and to correlate the grade of tumour with $\mathrm{P} 21$ expression.

\section{REVIEW OF LITERATURE:}

Gastric cancer is the 2 nd most common cancer in men and $4^{\text {th }}$ most common cancer in women ${ }^{(5)}$. The incidence of stomach cancer varies between different countries due to environmental factors, socioeconomic status, diet and H.pylori infection. rarely seen under the age group of 30years ${ }^{(6)}$. In India, the peak incidence has been found to be at a slightly lower age group compared to Western population ${ }^{(7)}$. In south India age range is around 35 to 55 years ${ }^{(8)}$. Stomach cancers predominantly affects men than women, with sex ratio of around 2:1 ${ }^{(9)}$

H.pylori infection is one of the most important risk factor which is more common in low socioeconomic status and can be a precursor of mainly intestinal type of gastric cancer. Long standing H.pylori infection will cause inflammation of the gastric mucosa that progressively cause atrophic changes and slowly convert the gastric mucosa into the intestinal type of mucosa. But, not all the infected patients will develop cancer and also sometimes gastric cancer develops in a background without any preceding infection ${ }^{(10)}$. Chronic gastritis causes hypochlorhydria and favours colonization of H.pylori infection. Those peoples with habit of tobacco chewing and smoking were found to have increased risk of stomach cancer especially in India ${ }^{(11)}$.

The gastric cancer patients usually presents with anorexia with loss of weight, dyspepsia and pain abdomen. Gastric outlet obstruction occurs more commonly with bulky tumours. Ulcerative tumours can lead to hematemesis or melaena ${ }^{(12)}$.

Partial gastrectomy leads to reflux of bilious, alkaline intestinal fluid which causes intestinal metaplasia. Barrett oesophagus also has increased risk of adenocarcinoma of gastroesophageal junction ${ }^{(13)}$. Gastric adenomas are one of the precursor lesions that progress to gastric adenocarcinoma.

Many classification systems has been proposed for gastric carcinoma. Lauren classified gastric cancer into two subtypes, intestinal and diffuse type. $86 \%$ of gastric cancers fit into these two subtypes. Other subtypes are mixed intestinal and diffuse and uncommon variants ${ }^{(14)}$. Due to the simplicity of Lauren classification, it can be used for epidemiologic studies but cannot be used to assess the outcome of the tumors. Hence, WHO assigns the grades to adenocarcinoma based on the degree of differentiation and its similarity to 
metaplastic intestinal tissue into Well differentiated, Moderately differentiated \& Poorly differentiated grades ${ }^{(15)}$.

In the past several decades the incidence of gastric cancer started decreasing in the entire world population. But these changes in incidence, point towards the tumors arising in the non cardiac sites only, whereas proximal gastric cancers arising from the cardia and the gastroesophageal junction has started increasing in the world. These changes suggest that tumors located at cardiac end of stomach have a separate molecular pathway from that of non cardiac site tumors ${ }^{(16,17)}$.

Genetic factors play an important role in diffuse type gastric carcinoma which usually occurs in younger population ${ }^{(13)}$.

Gastric carcinoma has highly complicated carcinogenetic pathway which is a multiple step process that involves gene and environment interactions.

Gastric carcinogenesis has a complicated molecular pathway which includes both changes in genetics and epigenetics. These changes are amplification of cyclin $E$, inactivation of p53 due to point mutation and loss of heterozygosity, loss of p2land p27 cyclin dependent inhibitors expression \& loss of Retinoblastoma protein expression. P2l gene has been shown to mediate p53 functions and has been proven to be an inhibitor of cyclin-dependent kinases ${ }^{(18)}$. P21 expression reflects the growth suppressive function of P53. P21 functions as a cell cycle inhibitor and anti-proliferative effector in normal cells and in some cancers ${ }^{(19)}$.

The histotechniques which help to evaluate the presence of P21 expression are immunohistochemistry and reverse transcriptase polymerase chain reactions. Huang studied the relationship between the expressions of tumor suppressor proteins P21 and p53 and malignant growth of gastric carcinoma in 88 cases by immunohistochemical method ${ }^{(20)}$.

\section{MATERIALS AND METHODS:}

Fifty patients who underwent gastrectomy either partial or total gastrectomy for gastric carcinoma at Government Vellore Medical College \& Hospital, Vellore, Tamil Nadu, India were included in this study. All 50 patients were diagnosed as primary gastric adenocarcinoma by Gastroscopy with biopsy and underwent curative surgery. This retrospective study was conducted during the period from April 2018 to March 2020. Clinical data of the patients such as age, sex, presenting symptoms, risk factors like smoking, alcohol and tobacco chewing were obtained retrospectively from the biopsy register. Clinical data and lab investigation findings were tabulated.

Haematoxylin and Eosin stained sections of all the 50 cases included in this study were reviewed and analysed. Tumours were subtyped according to Lauren's classification system and graded according to WHO grading system. Formalin fixed paraffin embedded appropriate tumour blocks with adjacent normal gastric mucosa were chosen and evaluated for P21 expression by Immunohistochemical staining.

\section{STUDY DESIGN:}

Observational retrospective study.

\section{INCLUSION \& EXCLUSION CRITERIA:}

Fifty patients with complete clinical data \& diagnosed as gastric adenocarcinoma by histopathological examination were included and tumour blocks were retrospectively analysed for histopathological type and P21 expression. Tumours other than epithelial origin and those patients treated with preoperative chemotherapy and radiotherapy were excluded from the study.
OBSERVATION AND RESULTS:

In the present study, out of 50 cases studied $32(64 \%)$ were males and $18(36 \%)$ were females. Most of the cases (32 cases $64 \%$ ) were in the age group of above 50 years (Table: 1 ).

Table 1: Age and Sex distribution in 50 cases of Gastric Adenocarcinoma

\begin{tabular}{|l|l|l|l|}
\hline \multirow{2}{*}{ Age } & Male & Female & Total \\
\cline { 2 - 4 } & Number of cases & Number of cases & \\
\hline $21-30$ & 3 & 0 & 3 \\
\hline $31-40$ & 2 & 4 & 6 \\
\hline $41-50$ & 6 & 3 & 9 \\
\hline $51-60$ & 13 & 8 & 21 \\
\hline$>60$ & 8 & 3 & 11 \\
\hline Total & 32 & 18 & 50 \\
\hline
\end{tabular}

Of the 50 cases evaluated for risk factors, smoking and alcohol appears as major risk factor in males. Tobacco chewing was significantly associated with female patients ( Table:2).

Table 2: Assessment of risk factors in 50 patients of Gastric carcinoma

\begin{tabular}{|l|l|l|}
\hline Risk factors & Male & Female \\
\hline Smoking & 22 & 0 \\
\hline Alcohol & 10 & 0 \\
\hline Tobacco chewing & 2 & 8 \\
\hline
\end{tabular}

Loss of weight \& loss of appetite ( 46 cases) was found to be the commonest presenting symptom in majority of the cases. Dyspepsia (42 cases) was the second most common symptom followed by epigastric pain (35 cases), (Table:3).

Table 3: Clinical presentation in 50 cases of Gastric Adenocarcinoma

\begin{tabular}{|l|l|l|}
\hline Symptoms & Number of cases & $(\%)$ \\
\hline Loss of weight \& appetite & 46 & $92 \%$ \\
\hline Dyspepsia & 42 & $84 \%$ \\
\hline Epigastric pain & 35 & $70 \%$ \\
\hline Vomiting & 7 & $14 \%$ \\
\hline Melaena & 5 & $10 \%$ \\
\hline
\end{tabular}

Out of 50 cases evaluated for anatomical location of malignancy(Table:4), most of the cases (25cases- $50 \%$ ) showed tumor at the antrum of stomach, followed by body ( 16 cases $-32 \%$ ) and least number of cases were presented with tumour in cardiac region of stomach (9cases -18\%),(Figure: $1 \& 2)$.

Table :4. Anatomical Distribution of Gastric Adenocarcinoma in 50 cases.

\begin{tabular}{|l|l|l|}
\hline $\begin{array}{l}\text { Anatomical Location of } \\
\text { Tumour in Stomach: }\end{array}$ & $\begin{array}{l}\text { Number of } \\
\text { cases }\end{array}$ & Percentage \\
\hline Cardia & 9 & $18 \%$ \\
\hline Body & 16 & $32 \%$ \\
\hline Antrum & 25 & $50 \%$ \\
\hline & & \\
\hline
\end{tabular}

Figure:1. Total gastrectomy. Figure:2. Subtotal $\mathrm{C} / \mathrm{s}$ - Diffuse infiltrative tumor gastrectomy. involving entire thickness of $\mathrm{C} / \mathrm{s}$-Proliferative growth in the stomach wall. antrum of stomach.

Histopatholoy of all the 50 cases examined shows intestinal type in 36 cases $(72 \%)$ and diffuse type of gastric 
adenocarcinoma in 14 cases (28\%). Hence the predominant histological pattern of adenocarcinoma in this study was intestinal type(Table:5).

Table 5: Lauren Histopathological type in 50 cases of Gastric carcinoma

\begin{tabular}{|l|l|l|}
\hline Histopathological type & Number of cases & Percentage \\
\hline Intestinal type & 36 & $72 \%$ \\
\hline Diffuse type & 14 & $28 \%$ \\
\hline Total & 50 & $100 \%$ \\
\hline
\end{tabular}

Histopathological grading of tumors (Table:6) evaluated in this study showed, 22 cases (44\%) were moderately differentiated adenocarcinoma, followed by poorly differentiated tumors(Fig.3) accounting to 16 cases (32\%) and only 12 cases (24\%) were well differentiated grade(Fig.4).

Table 6: Histopathological Grading in 50 cases of Gastric Adenocarcinoma

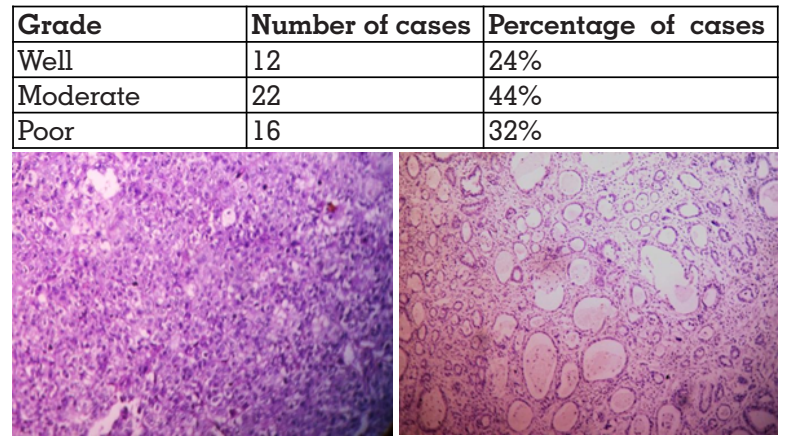

Figure:3. Poorly

differentiated

adenocarcinoma of

stomach. 10X (H\&E)-

Neoplastic cells arranged

in solid sheets

Immunohistochemical evaluation of P21 showed, intense nuclear staining in more than $25 \%$ of cancer cells in P21 positive cases(Figure:5) and less than $25 \%$ of cancer cells in negative cases(Figure:6).

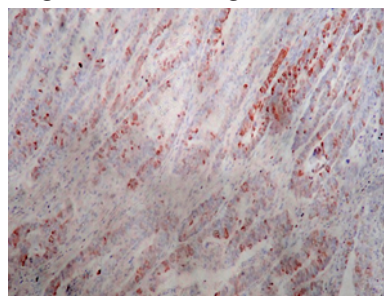

Figure:5. Well differentiated gastric adenocarcinoma P21 positive. P21 IHC Score 3 : $70 \%$ of the concer cells shows intense nuclear staining

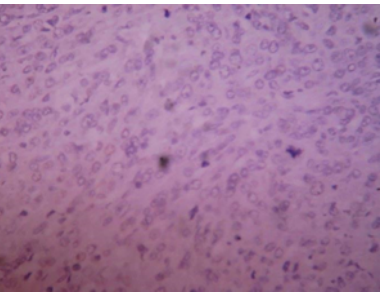

Figure:6. Poorly differentiated gastric adenocarcinoma - P21 Negative. P21 IHC Score 0 : Negative Staining

In this study, most of the well differentiated gastric adenocarcinoma ( $75 \%$ ) were positive for p2l expression. Most of the poorly differentiated cases ( $81 \%$ ) were negative for $\mathrm{p} 21$ expression and moderately differentiated tumours showed variable P2l expression(Table:7).

Table 7: P21 IHC Score with respect to Histological Grade in 50 Cases of Gastric Adenocarcinoma

\begin{tabular}{|l|l|l|l|l|l|l|}
\hline $\begin{array}{l}\text { P21 IHC } \\
\text { Exore \& } \\
\text { Expression }\end{array}$ & $\begin{array}{l}\text { Well } \\
\text { differentia } \\
\text { ted grade }\end{array}$ & $\%$ & $\begin{array}{l}\text { Moderately } \\
\text { differentiat } \\
\text { ed grade }\end{array}$ & $\%$ & $\begin{array}{l}\text { Poorly } \\
\text { differentiat } \\
\text { ed grade }\end{array}$ & $\%$ \\
\hline $\begin{array}{l}\text { 0\&l } \\
\text { (Negative) }\end{array}$ & 3 & $25 \%$ & 15 & $68 \%$ & 13 & $81 \%$ \\
\hline
\end{tabular}

\begin{tabular}{|l|l|l|l|l|l|l|}
\hline $\begin{array}{l}2,3 \& 4 \\
\text { (Positive) }\end{array}$ & 9 & $75 \%$ & 7 & $32 \%$ & 3 & $19 \%$ \\
\hline
\end{tabular}

\section{DISCUSSION:}

Clinical data of the patients such as age, sex, presenting symptoms, risk factors like smoking, alcohol and tobacco chewing were obtained retrospectively. The present study showed the occurance of gastric carcinoma in the age group ranging from 21 to 78 years with mean age of 52.2 years. Most of the cases were presented in the age group of more than 50 years (64\%). 32 patients were male and 18 patients were female with male : female ratio of $1.8: 1$, similar to the observation made by Yeole BB et al ${ }^{(9)}$.

The present study of gastric carcinoma showed significant association with smoking (22cases) and alcohol (10 cases) in males similar to Tominaga et $\mathrm{al}^{(21)}$ and Ko Cho et $\mathrm{al}^{(22)}$ study. From this study it was observed that tobacco chewing (8cases) had a significant associated risk factor in female patients presented with gastric adenocarcinoma.

Most common presenting symptoms with gastric carcinoma in the present study were loss of weight and appetite (92\%) followed by dyspepsia (84\%) and epigastric pain (70\%). Those patients with gastric outlet obstruction presented with vomiting(14\%). Similar to Wanebo et al ${ }^{(23)}$ study, the present study also showed loss of weight as the most common mode of presentation.

In majority of cases the tumors were located in the antrum of stomach (50\%) followed by body (32\%) and cardia (18\%). In the present study, intestinal type (36 cases-72\%) was more common than diffuse type (14cases $-28 \%$ ) of gastric adenocarcinoma. This study also showed increased occurrence of moderately differentiated adenocarcinoma (22 cases- $44 \%$ ), followed by poorly differentiated grade (16 cases- $32 \%$ ) and least well differentiated tumours(12cases $24 \%)$.

In the present study, 19 cases $(38 \%)$ were p2l positive and 3 lcases $(62 \%)$ were p2l negative. Intense nuclear staining was seen in more than $25 \%$ of cancer cells in P21 positive cases and less than $25 \%$ of cancer cells in negative cases. To evaluate the p2l expression and histological grade, tumours were divided into differentiated type (34 cases which includes both well and moderately differentiated adenocarcinoma) and undifferentiated type (16 cases which include poorly differentiated tumours ). P21 expression was found to be high in differentiated type (16 out of 34 cases were positive) with most of the well differentiated tumours $(75 \%)$ showed positivity for P21 expression, whereas moderately differentiated grade showed variable P2l expression and loss of P2l expression $(81 \%)$ was noted in most of the poorly differentiated tumors (13 out of 16 cases showed negative expression), similar to V.Michalaki et al study ${ }^{(24)}$.

\section{CONCLUSION:}

In this study it was observed that gastric adenocarcinoma more commonly affects people aged above 50 years. Males were twice more commonly affected by gastric carcinoma than females, with most common presenting symptoms were loss of weight and appetite followed by dyspepsia. Smoking and alcohol were the commonest risk factors for gastric cancer in men, whereas tobacco plays a major risk factor in women. The most common site of gastric carcinoma was antrum with Laurens intestinal type being the most prevalent histopathological tumour type.

P21 expression has a significant correlation with histological grade of tumour. Moderately differentiated gastric tumours showed variable P2l expression, most of the well differentiated tumours were positive for $\mathrm{p} 21$ expression and most of the poorly differentiated gastric adenocarcinomas 
were negative for $\mathrm{p} 21$ expression.

\section{SUMMARY:}

From this study we suggest that any patient aged above 50 years with symptoms of epigastric pain, dyspepsia with loss of appetite and weight has to be subjected to Gastroscopy with biopsy followed by histopathological examination along with immunohistochemical evaluation of P2l expression for early diagnosis of gastric adenocarcinoma.

\section{REFERENCES:}

1) Howlader N, Noone Am, Krapcho M, et al. Seer Cancer Statistics Review, 1975-2008.National Cancer Institute.2011.

2) Ferlay J, Shin Hr, Bray F, Forman D, Mathers C and Parkin Dm. Globocan 2008, Cancer Incidence and Mortality World wide. IARC 2010.

3) Nagini S. Gastric Cancer, Molecular Pathogenesis and chemoprevention. World J Gastrointest Oncol. 2012 ; July 15; 4(7): 156-169.

4) Lee KH, Lee HE, Cho SJ, Cho YJ, Lee HS, Kim JH, Nam SY, Chang MS, Kim WH, Lee BL. Immunohistochemical analysis of cell cycle-related molecules in gastric carcinoma: prognostic significance, correlation with clinicopathological parameters, proliferation and apoptosis. Pathobiology 2008:75: 364-372

5) Matthew J Bowles, Irving S Benjamin. Cancer of the stomach and pancreas. BMJ. 2001; December 15; 323(7326): 1413-1416

6) Nakamura T, Yao T, Niho Y, Tsuneyoshi M. A clinicopathological study in young Patients with Gastric carcinoma. J Surg Oncol.1999; 71:214-219.

7) Correa P. The Epidemiology of Gastric Cancer. World J Surg. 1991;15(2):228-34.

8) Keechilat Pavithran, Dinesh C. Doval, and Kamal K. Pandey. Gastric Cancer in India. Gastric Cancer. 2002; 5: 240-243.

9) Yeole BB. Trends in Cancer incidence in esophagus, stomach, colon, rectum and liver in males in India. Asian Pac J Cancer Prev. 2008; 9: 97-100.

10) Correa P. Helicobacter Pylori and Gastric carcinogenesis. Am J Surg Pathol .1995; 19: S37-S43.

11) G La Torre, G Chiaradia, F Gianfagna et al. Smoking Status and Gastric Cancer Risk: An updated meta-analysis of case-control studies published in the past ten years. Tumori. 2009; 95: 13-22.

12) Albert $C$ et al. Clinical Aspects of Gastric Cancer. Gastrointestinal Cancers: Biology, diagnosis, and therapy, Lippincot-Raven; 1995:197-216.

13) The Gastrointestinal Tract, Chapter 17. Robbins and Cotran Pathological Basis of Disease. 8th edition, Kumar, Abbas, Fausto (Saunders/ Elsevier) 2010:784-785.

14) Lauren $P$. The two histological main types of Gastric carcinoma. Diffuse and so-called Intestinal type carcinoma. Acta Pathol Microbiol Scand . 1965; 64:31-49.

15) Bosman FT, World Health Organization, International Agency for Research on Cancer. WHO Classification of Tumours of the Digestive System. Lyon: International Agency for Research on Cancer; 2010.

16) Correa P, Chen V. Gastric Cancer. In Doll R, Fraumeni JF, Muir CS: Trends in cancer incidence and mortality. Cold Spring Harbor, Ny: Cold Spring Harbor Laboratory Press. 1994; 55-76.

17) Stacy Carl-Mcgrath, Matthias Ebert, Christoph Rocken. Gastric Adenocarcinoma: Epidemiology, Pathology and Pathogenesis. Cancer Therapy.2007; 5,:877-894

18) Noda A, Ning Y, Venable SF, Pereira-Smith Om, and Smith JR. Cloning of Senescent Cell-Derived Inhibitors of DNA synthesis using an expression screen. Exp Cell Res.1994; 21 1: 90-98.

19) Bahar Shamloo and Sinem Usluer. P21 in cancer Research. Cancers: 2019;11,1178.

20) Huang J, Gan J. Relationship between expression of tumour suppressor protein P21 and P53 and cell proliferation in the gastric carcinoma. Hunan Yike Daxue Xuebao. 1998; 23: 441-443.

21) Tominaga $\mathrm{K}$ et al. A case-control study of stomach cancer and its genesis in relation to alcohol consumption, smoking and familial cancer history. Jpn J Cancer Res. 1991; 82: 974-79.

22) Ko JK, Cho $\mathrm{CH}$. Alcohol drinking and cigarette smoking-a partner for gastric ulceration. Zhonghua Yi Xue Za Zhi (Taipei). 2000; 63(12):845-854.

23) H J Wanebo, B J Kennedy et al. Cancer of the stomach. A patient care study by the American College of Surgeons. Ann Surg. 1993; November 218(5): 583-592.

24) V.Michalaki et al. Prognostic significance of cyclin Dl and P21(WAFl/CIP1) in gastric cancer. Annals of Oncology (supplement 2): iil-ii85, 2016 